九州大学学術情報リポジトリ

Kyushu University Institutional Repository

\title{
Ultrahigh strength and high plasticity in TiAl intermetallics with bimodal grain structure and nanotwins
}

\section{Edalati, Kaveh}

Department of Materials Science and Engineering, Faculty of Engineering, Kyushu University I WPI, International Institute for Carbon-Neutral Energy Research (WPI-I2CNER), Kyushu University

Toh, Shoichi

Research Laboratory for High Voltage Electron Microscopy, Kyushu University

Iwaoka, Hideaki

Department of Materials Science and Engineering, Faculty of Engineering, Kyushu University

Watanabe, Masashi

Department of Materials Science and Engineering, Lehigh University

他

http://hdl. handle. net/2324/26378

出版情報：Scripta Materialia. 67 (10)，pp.814-817，2012-11. Elsevier バージョン：

権利関係: (C) 2012 Acta Materialia Inc. 


\title{
Ultrahigh strength and high plasticity in TiAl intermetallics with bimodal grain structure and nanotwins
}

\author{
Kaveh Edalati, ${ }^{\mathrm{a}, \mathrm{b}, *}$ Shoichi Toh, ${ }^{\mathrm{c}}$ Hideaki Iwaoka, ${ }^{\mathrm{a}}$ Masashi Watanabe, ${ }^{\mathrm{d}}$ \\ Zenji Horita, ${ }^{\text {a,b }}$ Daisuke Kashioka, ${ }^{\mathrm{e}}$ Kyosuke Kishida ${ }^{\mathrm{e}}$ and Haruyuki Inui ${ }^{\mathrm{e}}$
}

${ }^{\mathrm{a} D e p a r t m e n t ~ o f ~ M a t e r i a l s ~ S c i e n c e ~ a n d ~ E n g i n e e r i n g, ~ F a c u l t y ~ o f ~ E n g i n e e r i n g, ~ K y u s h u ~ U n i v e r s i t y, ~}$ Fukuoka 819-0395, Japan

${ }^{b}$ WPI, International Institute for Carbon-Neutral Energy Research (WPI-I2CNER), Kyushu University, Fukuoka 819-0395, Japan

${ }^{\mathrm{c}}$ Research Laboratory for High Voltage Electron Microscopy, Kyushu University, Fukuoka 819-0395, Japan

${ }^{\mathrm{d} D e p a r t m e n t ~ o f ~ M a t e r i a l s ~ S c i e n c e ~ a n d ~ E n g i n e e r i n g, ~ L e h i g h ~ U n i v e r s i t y, ~ B e t h l e h e m, ~ P A ~ 18015, ~ U S A ~}$ ${ }^{\mathrm{e}}$ Department of Materials Science and Engineering, Faculty of Engineering, Kyoto University, Kyoto 606-8501, Japan

\footnotetext{
Abstract

Nanostructured intermetallics generally exhibit high strength but limited plasticity due to the covalent nature of their bonding. In this study, high-pressure torsion followed by annealing was used to produce TiAl intermetallics with two microstructural features: (i) bimodal microstructure composed of nanograins and submicrometer grains; and (ii) nanotwins. An exceptional performance, combining ultrahigh yield strength, $2.9 \mathrm{GPa}$, and high strain to failure, $14 \%$, was achieved with micropillar compression tests. Twinning, dislocation slip and grain boundary sliding appear to be active under compressive stress.

Keywords: Nanostructure; High-pressure torsion (HPT); Severe plastic deformation (SPD), Stacking fault energy; Ductility.

* Corresponding author at: Department of Materials Science and Engineering, Faculty of Engineering, Kyushu University, Fukuoka 819-0395, Japan. Tel./fax: +81 92802 2992; e-mail: kaveh.edalati@zaiko6.zaiko.kyushu-u.ac.jp.
} 
Intermetallics, which are ordered chemical compounds comprising two or more metals, are generally hard and brittle at room temperature. These mechanical features are a consequence of strong atomic bondings due to rather covalent than metallic bonding, which make dislocation motion through the crystalline structure difficult [1]. Although a number of approaches have been used to improve these materials' mechanical properties, such as grain refinement and addition of alloying elements, there is always a trade-off between strength and plasticity [2]. Although intermetallics refined to the nanometer level exhibit superior physical properties as well as high strength to weight ratios [3] and even superplasticity at elevated temperatures [4], their main weakness remains their brittleness at room temperature [1,2].

Previous studies have reported that the large fraction of grain boundaries acts as both dislocation sources and sinks so that dislocation accumulation, strain hardening and plasticity become limited in nanostructured materials [5,6]. In order to improve the ductility (plasticity under tensile stress), a number of strategies have been employed in metallic alloys, such as severe plastic deformation (SPD) [7-10], bimodal microstructure formation [11-13], introduction of nanotwins [14-16], gradient structure formation from coarse grains to nanograins [17], introduction of precipitates [18], introduction of nanotwins and lattice softening [19], etc. [20]. In this study, a combination of the two strategies mentioned above, namely bimodal microstructure and nanotwin formation, are applied to intermetallics and an ultrahigh strength and high malleability (plasticity under compressive stress) are attained in an TiAl intermetallic.

Disc samples (10 mm diameter, $0.8 \mathrm{~mm}$ thickness) of TiAl intermetallics were prepared from Al-50 mol.\% Ti micropowder mixtures by SPD followed by annealing, using an approach developed in a previous study for AlNi [21]. Al (99.99\%) powders had particle sizes less than $\sim 75$ $\mu \mathrm{m}$ and $\mathrm{Ti}$ (99.9\%) powders had particle sizes less than $\sim 150 \mu \mathrm{m}$. The powder mixtures were subjected to SPD using high-pressure torsion (HPT) [22,23] under a pressure of $6 \mathrm{GPa}$ and concurrent rotation of 50 turns with a rotation speed of $1 \mathrm{rpm}$ at $573 \mathrm{~K}$. Following the HPT, Al was completely transformed into Al-rich intermetallics such as $\mathrm{TiAl}_{3}, \mathrm{TiAl}_{2}$ and $\mathrm{TiAl}$, and a saturation of grain refinement [24,25] to the nanometer level was achieved throughout the discs. The HPT-processed samples were subsequently annealed at $873 \mathrm{~K}$ for $86.4 \mathrm{ks}$ to complete the reactions and produce TiAl with bimodal microstructures and nanotwins.

The samples were evaluated by means of X-ray diffraction (XRD) analysis, differential scanning calorimetry (DSC), Vickers microhardness measurement, compression testing using square-shaped micropillars [26] (side length: 0.7-11.3 $\mu \mathrm{m}$, height: three times the the length), electron back-scatter diffraction (EBSD) analysis, scanning electron microscopy (SEM) and scanning transmission electron microscopy (STEM).

The materials and processing parameters were selected carefully to produce several characteristic features as shown in Figure 1. First, the average grain size of sample reaches $\sim 20 \mathrm{~nm}$ after SPD (Fig. 1d), whereas the grain size of severely deformed metallic materials is usually larger than $100 \mathrm{~nm}[27,28]$. Here, the grain refinement is enhanced by using the powder mixtures [24], by combining the solid-state reactions and SPD [29] and by strong atomic bonding of Al-rich intermetallics [25]. Second, in addition to ordinary and superlattice slip deformation modes, 
the TiAl exhibits deformation twinning [30]. Moreover, the stacking fault energy of TiAl is low, $100 \mathrm{~mJ} \mathrm{~m}^{-2}$ [31], and the materials exhibit nanotwin formation by annealing (Fig. 1a-c). The twin width ranges from few nanometers to $\sim 50 \mathrm{~nm}$, with an average twin width of $\sim 9 \mathrm{~nm}$ (Fig. 1e). It should be noted that since only the twins with twin boundaries parallel to the incident electron beam are visible in TEM images, the real twin density should be much higher than the one seen in Figure 1. Third, the annealing temperature of 873 Kis selected slightly higher than the temperature peaks appeared during DSC analysis of the HPT-processed samples (478, 652, 810 and $844 \mathrm{~K}$ ) to ensure that all reactions are completed to form the TiAl intermetallic. It should be noted that both XRD and selected-area electron diffraction (SAED) analyses demonstrate that the TiAl intermetallic is formed after the annealing. Fourth, although the solid-state reactions are completed after annealing for $3.6 \mathrm{ks}$, the annealing time was deliberately selected longer for 86.4 ks to produce a bimodal microstructure with an average grain size of $\sim 100 \mathrm{~nm}$ composed of nanograins with grain sizes less than $100 \mathrm{~nm}$, and submicrometer grains with grain sizes larger than $100 \mathrm{~nm}$ (Fig. 1d). The formation of the bimodal microstructure after the annealing was confirmed by STEM and EBSD analysis.
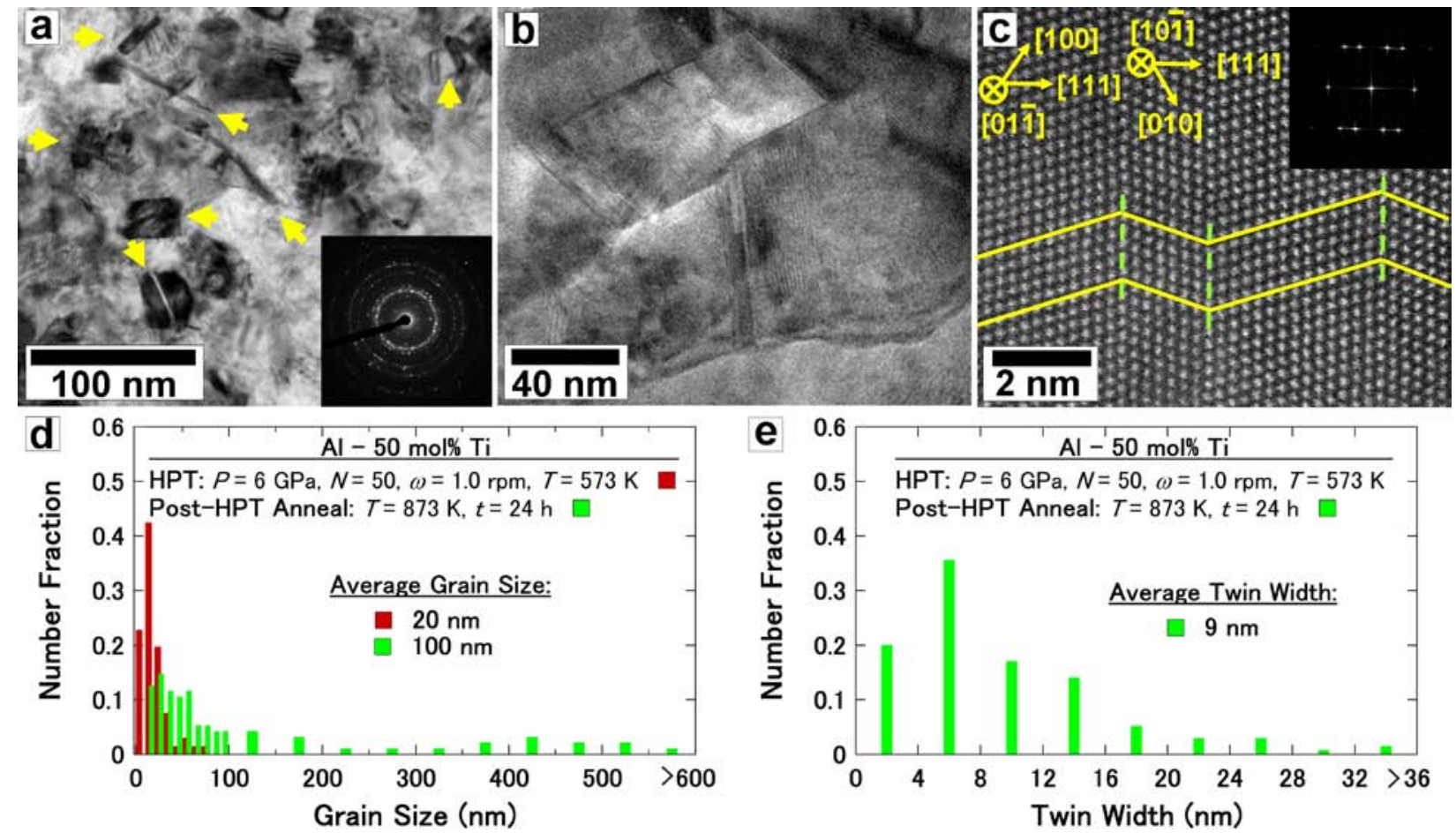

Figure 1. Microstructures of TiAl intermetallic. (a) TEM bright-field image and corresponding SAED pattern of nanograined structure with nanotwins indicated by arrows; (b) TEM bright-field image of a single submicrometer grain containing several twins; (c) STEM lattice image of nanotwins and corresponding diffractogram; (d) grain size distribution for HPT-processed samples before and after annealing; and (e) twin width distribution after annealing.

Despite the grain growth to $\sim 100 \mathrm{~nm}$ from $\sim 20 \mathrm{~nm}$ due to the annealing, the steady-state hardness is increased to $705 \mathrm{Hv}$ above the hardness of $540 \mathrm{Hv}$ before the annealing. This hardness 
increase arises because of the formation of TiAl phase with a large fraction of twin boundaries. It is noted that the hardness-strain behavior of the $\mathrm{Al} / \mathrm{Ti}$ powder mixtures was, as reported earlier in the $\mathrm{Al} / \mathrm{Ni}$ powder mixtures [21], such that the hardness was about $100 \mathrm{Hv}$ until a significant increase occurred at shear strains of 50-100 and, with a further increase in the strain, the hardness saturates to a steady-state level of $540 \mathrm{Hv}$.

Two representative stress-strain curves of the samples before and after the annealing are delineated in Figure 2a from micropillar compression testing conducted at room temperature with a pillar size of $\sim 4 \times 4 \times 12 \mu \mathrm{m}^{3}$. Since some fractions of micropores are formed during HPT [21], the micropillar compression test was used in this study to minimize the effect of micropores on the mechanical properties. Moreover, the micropillars are appropriate to investigate the deformation mechanism [32]. The sample after HPT but before annealing, which consists of certain fractions of $\mathrm{Ti}, \mathrm{TiAl}_{3}, \mathrm{TiAl}_{2}$ and TiAl, exhibits a high yield strength, $1.7 \mathrm{GPa}$, but a limited malleability, 2\%. The sample after subsequent annealing, which contains TiAl, exhibits a high malleability, 23\%, and an enhanced yield strength of $\sim 3$ GPa, which is 4-10 times higher than that for micropillars of TiAl single crystals [26].
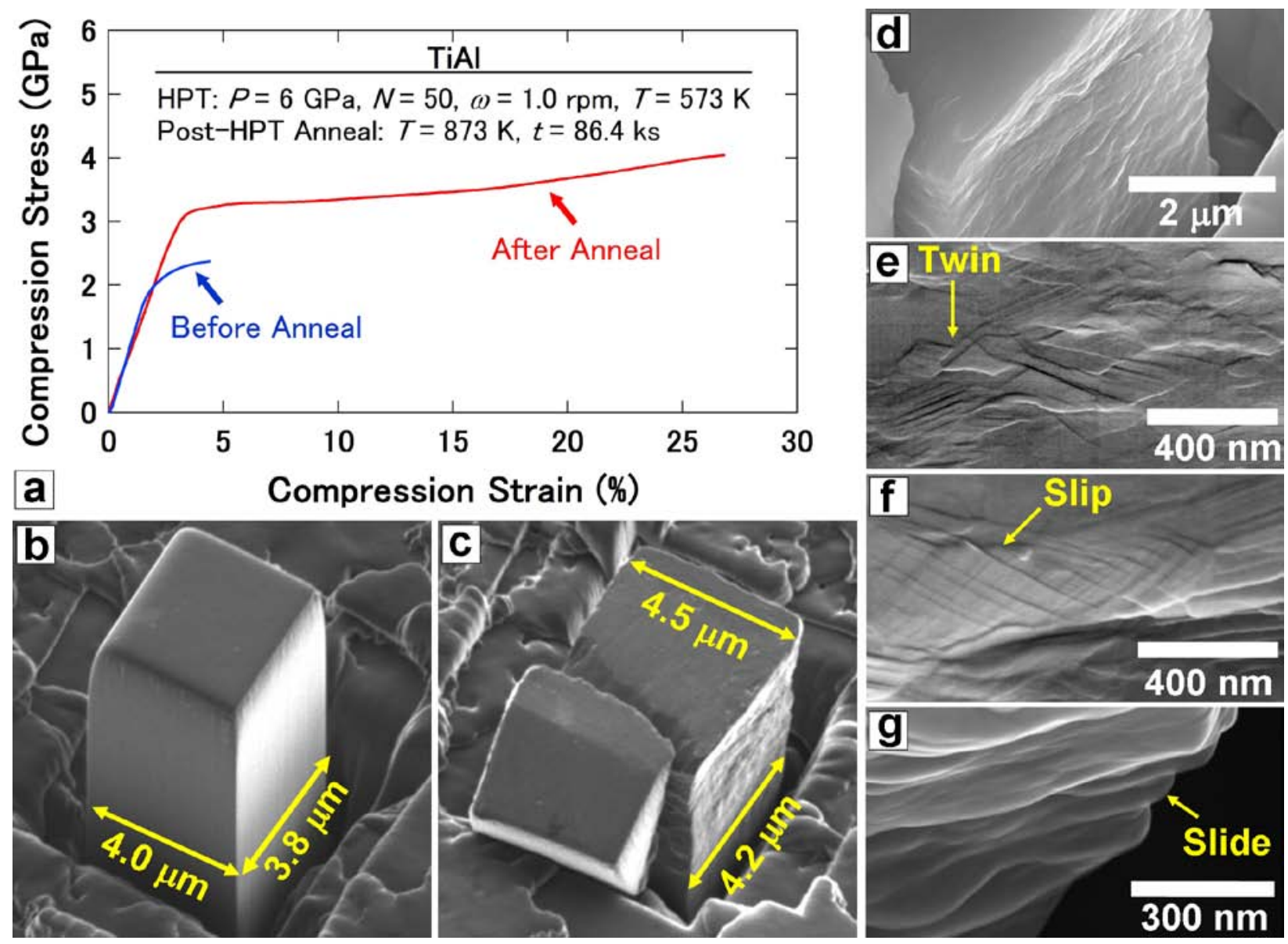

Figure 2. Micropillar compression test for TiAl intermetallic. (a) Nominal compression stress vs. nominal compression strain curves of HPT-processed samples before and after annealing, (b) appearance of pillar before compression, (c,d) appearance of pillar after compression, (e-g) SEM micrographs taken from pillar side surface and edge after compression. 
Observations of the TiAl micropillars before and after annealing, as shown in Figure 2b and c, reveal that the pillar is deformed plastically with an estimated uniform malleability of $\mathrm{e}=1-\mathrm{A}_{0} / \mathrm{A}=$ $\sim 19 \%\left(\mathrm{~A}_{0}=3.8 \times 4.0 \mu \mathrm{m}^{2}\right.$, area before deformation; $\mathrm{A}=4.2 \times 4.5 \mu \mathrm{m}^{2}$, area after deformation). The uniform malleability in this TiAl intermetallic is much higher than those reported in other nanostructured intermetallics [2]. The high uniform malleability may be due

to several reasons: (i) the presence of bimodal microstructure and nanotwins before deformation; (ii) the activation of different plastic deformation mechanisms during the deformation; and (iii) the effect of pillar size on the strength and malleability.

In pure metals and alloys, it is well established that a better combination of high strength and high plasticity is achieved with bimodal grain-size distribution when compared to nanograined structure. It has been demonstrated that nanograins contribute to strengthening, whereas good plasticity is due to the coarse grains [11-13]. Furthermore, pinning the dislocation motion and strengthening induced by coherent twin boundaries leads to less degradation of plasticity in comparison with those caused by incoherent grain boundaries because the twin boundaries have higher capacity for generation, accumulation and glide of the dislocations along their boundaries [14-16].

SEM micrographs taken from the side view of the pillar, shown in Figure 2d-g, indicate that high malleability is accompanied with significant nanoscale deformation. Moreover, Figure 2e and $\mathrm{f}$ clearly confirm that many twins and fine slip bands become active during the deformation, and Figure $2 \mathrm{~g}$ indicates that the sliding between the grains may also have occurred during the deformation. Earlier studies showed that grain boundary sliding is facilitated in ultrafine-grained metallic materials even at room temperature [33-35].

It is known that the pillar size influences the strength and plasticity of materials [36-38]. Figure 3 shows that the yield stress is somewhat lower and malleability and ultimate strength are higher for $0.7 \mu \mathrm{m}$ pillar size, but the size effect on the strength and plasticity is negligible and all mechanical properties are approximately at the steady state as long as the pillar size is larger than $\sim 2 \mu \mathrm{m}$. The size effect should be due to nonuniform distribution of stress as well as due to the effect of pillar surface on dislocation activities. The pillar surface acts not only as dislocation source, but also as a dislocation sink [38]. Dislocation pinning by pillar surface and subsequent pile-ups occur during micropillar compression, which results in lower local stress needed to sustain plastic flow, but higher strain hardening and plasticity. When the number of grains in the pillar volume (ratio of grain boundaries to pillar surface) increases or the dislocation pile-up becomes limited, the size effect is lowered. The mechanical properties become independent of the pillar size when the ratio of the pillar size to the grain size is higher than a critical value.

The results of micropillar compression tests (pillar size $>2 \mu \mathrm{m}$ ) are plotted in Figure 4 in comparison with relevant data [2], including coarse-grained and nanograined TiAl intermetallics with and without addition of alloying elements. A solid line represents the optimum relation between strength and ductility obtained by different TiAl intermetallics. There is a trade-off relationship between the strength and strain to failure; however, TiAl with bimodal microstructure and nanotwins provides important advantages over other materials. First, the strength of the 
material is significantly enhanced to a level three times higher than that for nanograined pure TiAl. Second, having improved the plasticity, its strength exceeds that of TiAl intermetallics with alloying elements. As discussed above, the ultrahigh strength and high plasticity obtained in this study, which appear to be independent of the pillar size, are due to two main microstructural features: (i) bimodal microstructure and (ii) nanotwins. It was confirmed that different plastic deformation mechanisms such as twinning, dislocation slip and grain boundary sliding become active during the compression of this designated intermetallic.
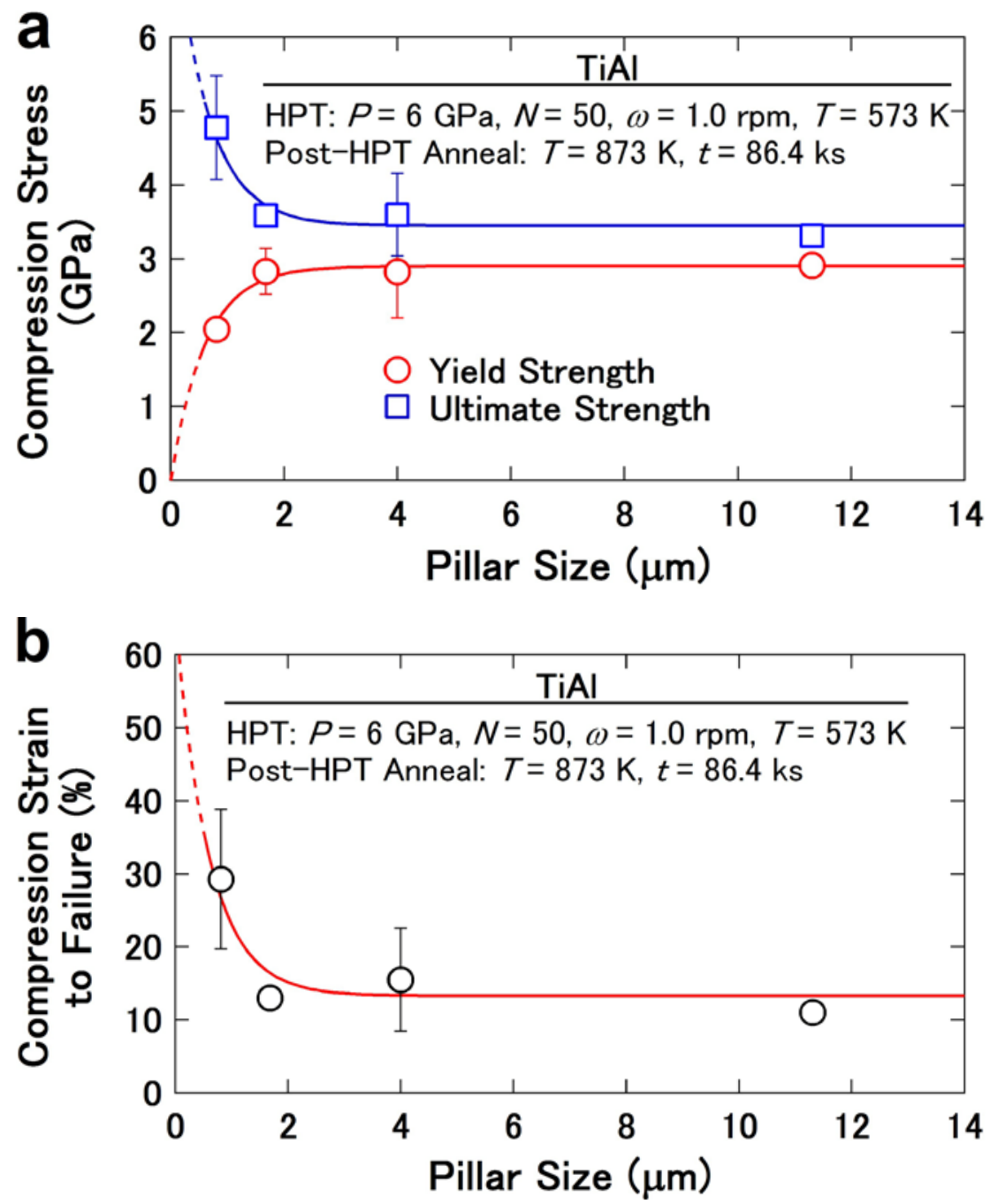

Figure 3. Influence of micropillar size on (a) yield and ultimate compression strength and (b) compression strain to failure.

In summary, a TiAl intermetallic with ultrahigh strength and high plasticity was developed by a combination of two strategies, namely bimodal microstructure formation and nanotwin formation. The strategies used in this study are applicable to the production of other nanostructured intermetallics with ultrahigh strength: we have produced several intermetallics in the Al-Ti-Ni system with yield strengths up to $3.5 \mathrm{GPa}$. However, in order to have high ductility, the stacking fault energy of the intermetallics should be low enough to form nanotwins by subsequent annealing. 


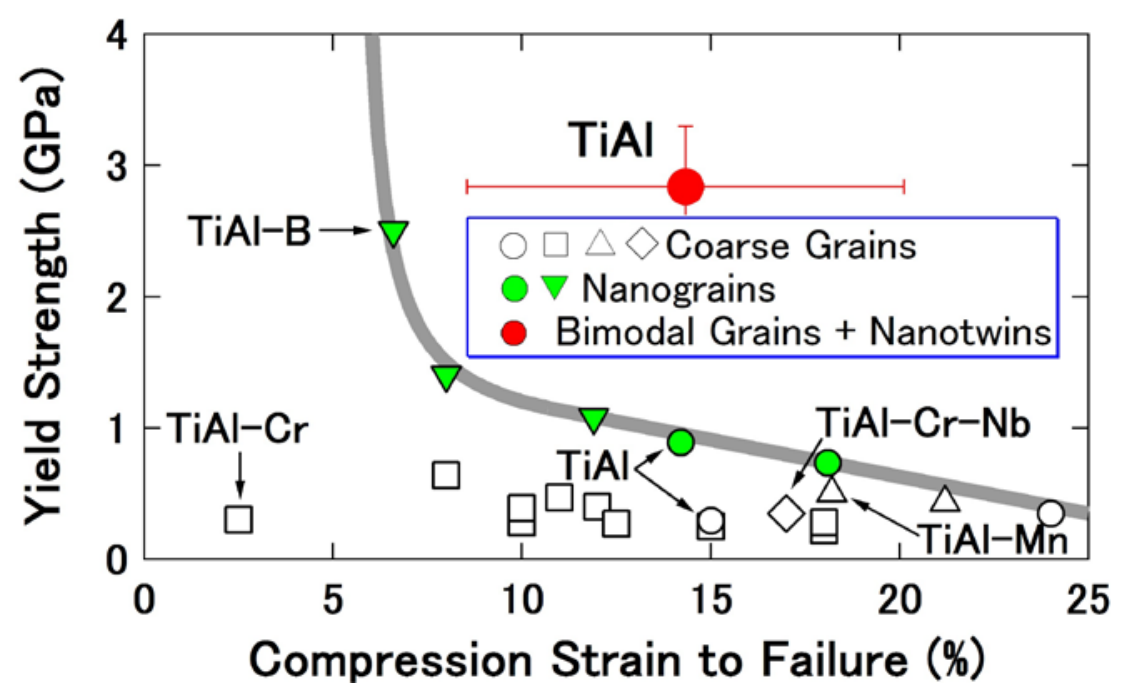

Figure 4. Plots of compression yield strength vs. compression strain to failure for TiAl with bimodal microstructure and nanotwins. Data for coarse- and nanograined high-purity TiAl and coarse- and nanograined TiAl with alloying additives from Ref. [2] are also included.

One of the authors (K.E.) thanks the Japan Society for Promotion of Science (JSPS) for a postdoctoral scholarship. This work was supported in part through grant DMR-0804528 from National Science Foundation, USA, in part by the Light Metals Education Foundation of Japan, in part by a Grant-in-Aid for Scientific Research from the MEXT, Japan, in Innovative Areas "Bulk Nanostructured Metals”, in part by Kyushu University Interdisciplinary Programs in Education and Projects in Research Development, in part by Grant-in-Aid for Scientific Research (A) (no. 24246113) from the MEXT, Japan, and in part by the Advanced Low Carbon Technology Research and Development Program of the Japan Science and Technology Agency (JST).

[1] N.S. Stoloff, V.K. Sikka, Physical Metallurgy and Processing of Intermetallic Compounds, Chapman \& Hall, London, 1996.

[2] T.W. Kim, R. Wagner, M. Yamaguchi (Eds.), Gamma Titanium Aluminides, TMS, Warrendale, PA, 1995.

[3] H. Gleiter, Prog. Mater. Sci. 33 (1989) 223-315.

[4] S.X. McFadden, R.S. Mishra, R.Z. Valiev, A.P. Zhilyaev, A.K. Mukherjee, Nature 398 (1999) 684-686.

[5] Z. Budrovic, P.M. Derlet, S.V. Petegem, B. Schmitt, Science 304 (2004) 273-276.

[6] M.A. Meyers, A. Mishra, D.J. Benson, Prog. Mater. Sci. 51 (2006) 427-556.

[7] R.Z. Valiev, I.V. Alexandrov, Y.T. Zhu, T.C. Lowe, J. Mater. Res. 17 (2002) 5-8.

[8] C.C. Koch, Scripta Mater. 49 (657) (2003) 657-662.

[9] R.Z. Valiev, Nature Mater. 3 (2004) 511-516.

[10] Y.T. Zhu, X.Z. Liao, Nature Mater. 3 (2004) 351-352. 
[11] V.L. Tellkamp, A. Melmed, E.J. Lavernia, Metall. Mater. Trans. A 32 (2001) 2335-2343.

[12] Y. Wang, M. Chen, F. Zhou, E. Ma, Nature 419 (2002) 912-915.

[13] B.Q. Han, Z. Lee, D. Witkin, S. Nutt, E.J. Lavernia, Metall. Mater. Trans. A 36 (2005) 957-965.

[14] L. Lu, Y.F. Shen, X.H. Chen, L.H. Qian, K. Lu, Science 304 (2004) 422-426.

[15] Y.H. Zhao, J.F. Bingert, X.Z. Liao, B.Z. Cui, K. Han, A.V. Sergueeva, A.K. Mukherjee, R.Z. Valiev, T.G. Langdon, Y.T. Zhu, Adv. Mater. 18 (2006) 2949-2953.

[16] K. Lu, L. Lu, S. Suresh, Science 324 (2009) 349-352.

[17] T.H. Fang, W.L. Li, N.R. Tao, K. Lu, Science 331 (2011) 1587-1590.

[18] Z. Horita, K. Ohashi, T. Fujita, K. Kaneko, T.G. Langdon, Adv. Mater. 17 (2005) 1599-1602.

[19] K. Edalati, S. Toh, T. Furuta, S. Kuramoto, M. Watanabe, Z. Horita, Scripta Mater. 67 (2012) 511-514.

[20] E. Ma, JOM 58 (4) (2006) 49-53.

[21] K. Edalati, S. Toh, M. Watanabe, Z. Horita, Scripta Mater. 66 (2012) 386-389.

[22] R.Z. Valiev, Y. Estrin, Z. Horita, T.G. Langdon, M.J. Zehetbauer, Y.T. Zhu, JOM 58 (4) (2006) 33-39.

[23] A.P. Zhilyaev, T.G. Langdon, Prog. Mater. Sci. 53 (2008) 893-979.

[24] R. Pippan, S. Scheriau, A. Taylor, M. Hafok, A. Hohenwarter, A. Bachmaier, Annu. Rev. Mater. Res. 40 (2010) 319-343.

[25] K. Edalati, Z. Horita, Acta Mater. 59 (2011) 6831-6836.

[26] K. Fujimura, K. Kishida, K. Tanaka, H. Inui, Mater. Res. Soc. Symp. Proc. 1295 (2011) 201-206.

[27] R.Z. Valiev, R.K. Islamgaliev, I.V. Alexandrov, Prog. Mater. Sci. 45 (2000) 103-189.

[28] M. Kawasaki, R.B. Figueiredo, T.G. Langdon, Acta Mater. 59 (2011) 308-316.

[29] N. Tsuji, T. Maki, Scripta Mater. 60 (2009) 1044-1049.

[30] H. Inui, M. Matsumura, D.H. Wu, M. Yamaguchi, Philos. Mag. A 75 (1997) 395-423.

[31] W.J. Zhang, F. Appel, Mater. Sci. Eng. A 334 (2002) 59-64.

[32] Y.B. Wang, D.D. Que, X.H. Wang, Y. Cao, X.Z. Liao, M. Kawasaki, S.P. Ringer, Z.W. Shan, T.G. Langdon, J. Shen, Acta Mater. 60 (2012) 253-260.

[33] R.Z. Valiev, E.V. Kozlov, Y.F. Ivanov, J. Lian, A.A. Nazarov, B. Baudelet, Acta Metall. Mater. 42 (1994) 2467-2475.

[34] N.Q. Chinh, P. Szommer, Z. Horita, T.G. Langdon, Adv. Mater. 18 (2006) 34-39.

[35] K.V. Ivanov, E.V. Naydenkin, Scripta Mater. 66 (2012) 511-514.

[36] D.C. Jang, J.R. Greer, Nature Mater. 9 (2010) 215-219.

[37] M.D. Uchic, D.M. Dimiduk, J.N. Florando, W.D. Nix, Science 305 (2004) 986-989.

[38] M.D. Uchic, P.A. Shade, D.M. Dimiduk, Annu. Rev. Mater. Res. 39 (2009) 361-386. 